\title{
Settlement process of radioactive dust to the ground inferred from the atmospheric electric field measurement
}

\author{
M. Yamauchi ${ }^{1}$, M. Takeda ${ }^{2}$, M. Makino ${ }^{3}$, T. Owada ${ }^{4}$, and I. Miyagi ${ }^{3}$ \\ ${ }^{1}$ Swedish Institute of Space Physics, Box 812, 98128 Kiruna, Sweden \\ ${ }^{2}$ Data Analysis Center for Geomagnetism and Space Magnetism, Faculty of Science, Kyoto University, Japan \\ ${ }^{3}$ National Institute of Advanced Industrial Science and Technology, Tsukuba, Japan \\ ${ }^{4}$ Kakioka Magnetic Observatory, Japan Meteorological Agency, Ishioka, Japan \\ Correspondence to: M. Yamauchi (m.yamauchi@irf.se)
}

Received: 28 June 2011 - Revised: 5 October 2011 - Accepted: 24 November 2011 - Published: 5 January 2012

\begin{abstract}
Radioactive materials from the accident at Fukushima Dai-ichi nuclear power plant (FNPP) in March 2011 spread over a large area, increasing the atmospheric electric conductivity by their ionizing effect, and reducing the vertical (downward) component of the DC electric field near the ground, or potential gradient (PG). PG data at Kakioka, $150 \mathrm{~km}$ away from the FNPP, showed independent changes compared to the radiation dose rate, and a comparison of these data revealed the local dynamics of the radioactive dust.
\end{abstract}

(1) The initial drop of the PG to almost zero during 14-15 March is most likely due to radioactive dust suspended in the air near the ground during cloudy weather. (2) An episode of PG increase to more than $50 \mathrm{~V} \mathrm{~m}^{-1}$ on 16 March is most likely due to the re-suspension of the radioactive dust from the surface and subsequent removal from Kakioka by the strong wind from the non-contaminated area. (3) Low but finite values of the PG during 16-20 March most likely reflect a reduced amount of radioactive material near the ground after the above wind transported away the majority of the suspended radioactive dust. (4) Very low values of the PG after substantial rain on 20-22 March most likely reflect settlement of the radioactive material by rain-induced fallout. (5) Temporal recovery of daily variations from the end of March to the middle of April with low nighttime fair-weather baseline PG most likely reflects re-suspension of the radioactive dust into the air from the ground and trees, and subsequent transport to the other region or fallout to the ground until late April. (6) Weakening of the daily variation and gradual recovery of the nighttime fair-weather baseline after mid-April suggests a complete settlement of the radioactive material to the ground with partial migration to the subsurface.
Keywords. Atmospheric composition and structure (Aerosols and particles; Pollution - urban and regional) - Meteorology and atmospheric dynamics (Atmospheric electricity)

\section{Introduction}

The accident at the Fukushima Dai-ichi nuclear power plant (FNPP) that was triggered by the Tohoku Earthquake on 11 March 2011 caused a release of a massive amount of radioactive material. Although the total amount of the radioactive material released by the Fukushima Accident $\left(10^{17} \mathrm{~Bq}\right.$ for Iodine ${ }^{131} \mathrm{I}$ and $10^{16} \mathrm{~Bq}$ for Cesium ${ }^{137} \mathrm{Cs}$ according to NISA, 2011) is less than that from the Chernobyl disaster on 26 April 1986, it still caused a substantial contamination of an area of several hundreds kilometer in diameter. A map of the contamination level has been obtained after a large number of soil sampling was analyzed using manpower (MEXT, 2011). However, dynamics of the radioactive dust and temporal change of the inter-regional contamination have not been well understood for both primary and secondary contamination. For the future planning for health protection and agricultural/fishery activities, it is important to understand the settlement process of the radioactive materials to the soil as well as the secondary transport, including daily dynamics by wind blowing or rain. Therefore, any methods to diagnose the transport and dynamics of the radioactive materials are useful.

We use here the vertical (downward) component of the atmospheric electric field, or potential gradient (PG), and combine it with the radiation dose rate data. Large-scale DC 
electric current is flowing in the air between the ground and the ionosphere at a global scale (e.g. reviews by Rycroft et al., 2000, 2008; Williams, 2009). Since both the ionosphere and the ground are highly electrically conductive compared to the atmosphere, the current generates a relatively vertical electric field of about $100-150 \mathrm{~V} \mathrm{~m}^{-1}$ at ground level except near electrified clouds. The PG is affected by the atmospheric electric conductivity that is partly controlled by ionization rate and loss rate, obeying the ion balance equation (Rosen and Hofmann, 1981; Makino and Ogawa, 1985; Rycroft et al., 2008). Therefore, the PG decreases when local ionizing radiation increases (Pierce, 1959; Hamilton and Paren, 1967; Harrison, 2003). This effect is not significant for already-conductive ground or seawater, but it is significant for the near-ground atmosphere.

This mechanism actually caused quick PG drops by one order of magnitude within one to a few hours after raininduced radioactive fallouts (wet contamination) related to nuclear tests or to the Chernobyl disaster at PG stations at distances up to more than $1000 \mathrm{~km}$ from the test site or Chernobyl (Harris, 1955; Israelsson and Knudsen, 1986; Tuomi, 1988, 1989). The quick drop of PG was also observed at Kakioka, which is located $150 \mathrm{~km}$ southwest of the FNPP, after the first massive southbound release of radioactive material from the FNPP on 14 March 2011 (Takeda et al., 2011, hereafter referred to as Paper 1). The FNPP-related PG changes took place as a result of wind-driven low-altitude transport of the radioactive dust without rainfall (dry contamination). Therefore, the contamination forms of the radioactive materials near the ground during this drop is most likely different from those during the previous events of quick PG drops; i.e. radioactive fallout in the FNPP case is most likely suspended in the air near the ground surface or just attaching on the surface without strong binding to the soil matrix (IAEA, 2006, Sect. 3.1).

Ideally, the degree of the changes in the electric conductivity or local ion density is expected to reflect the level, form, and transport of the contaminated radioactive materials that have different spatial distribution compared to the ions. Therefore, the PG is expected to respond differently at the different phases of the settlement and dynamics of the FNPPorigin radioactive materials for the same amount of the contamination. In fact, the time profile of the PG at Kakioka is not well correlated to those of radiation dose rates at the nearest stations to Kakioka, as one can see in Fig. 1 (see next section for explanation). By comparing the simultaneous observations of the radiation dose rates and weather records, it is possible to interpret minor PG changes that reflect physical processes or dynamics of the local radioactive materials and local ions. We use 1-min resolution PG data at Kakioka and 1-h resolution data of the ground-level radiation dose rate and meteorological records.

\section{Observation}

Figure 1 shows 1-h averaged PG at Kakioka, radiation dose rate at Ibaraki-cho (25 km east of Kakioka) and rainfall from Kakioka during March-May 2011. The sensor uses the Water-Dropper Collector, and is placed at $2.55 \mathrm{~m}$ high with $1.17 \mathrm{~m}$ separation from the wall inside a house (Shigeno et al., 2001). The sampling rate is $1 \mathrm{~Hz}$. The earthquake caused power failure for about three days. The geographical locations of Kakioka, Ibaraki-cho, and the FNPP are shown in Fig. 2. The numbers (1) to (6) and the stepped blue lines refer to segments in the time series that are discussed below. Local noon is near 03 universal time (UT). The initial drop of PG to near-zero values at around $21 \mathrm{UT}, 14$ March together with the increase of the radiation dose rate have been reported in $\mathrm{Pa}-$ per 1, and interpreted as the signature of arrival of a massive amount of radioactive materials at Kakioka by low-altitude wind. We examine here the variation after 15 March.

Although the PG is affected by the ionizing radiation, the changes in the PG are not well correlated with the changes in the radiation dose rate. To show this, data in March are enlarged in Fig. 3. After the arrival of the radioactive materials at Kakioka on 14 March, radiation dose rate at both Ibarakicho and Mito ( $30 \mathrm{~km}$ northeast of Kakioka) showed spikelike increases lasting 1-3 h at around 03 UT and 20 UT on 15 March, and also at around 02 UT and 20 UT on 20 March. Apart from the first spike, the radiation dose rate stepped to a higher level after the spike than the value before the spike. Among these four events, only the last and largest increase occurred together with a substantial change in the PG. The PG increase on 16 March is related neither to the radiation dose rate nor to rain. Another example of non-correlation is the PG value: it is completely different between the first period and the third period for the same level of the radiation dose rate at Ibaraki-cho.

The spikes of radiation dose rate shown in Figs. 1b, 3b, and $3 \mathrm{f}$ between 13 and 20 March are observed when, and only when, the wind steadily blows from northeast, i.e. from the FNPP for a few hours, and are not necessarily related to rain. Even for the spikes observed together with the rain (20 UT on 15 March and 20 UT on 20 March), the timing of the rain and that of the spike of the radiation level are not exactly the same. The time profile of each spike is not exponential decay, and the exponential decay started after the spike was over. Since exponential decay generally corresponds to physical radioactive decay of radionuclides that contaminate the surface, the spike part should be caused by radiation sources that do not fallout to the ground, i.e. remain suspended in the air, without contributing significantly to the atmospheric electric conductivity near the ground. All these data indicate that wind carried a dense radioactive dust plume from the FNPP during the spikes, leaving only a part of the dust to fallout to the ground, and this fallout process is simply enhanced by rain. 

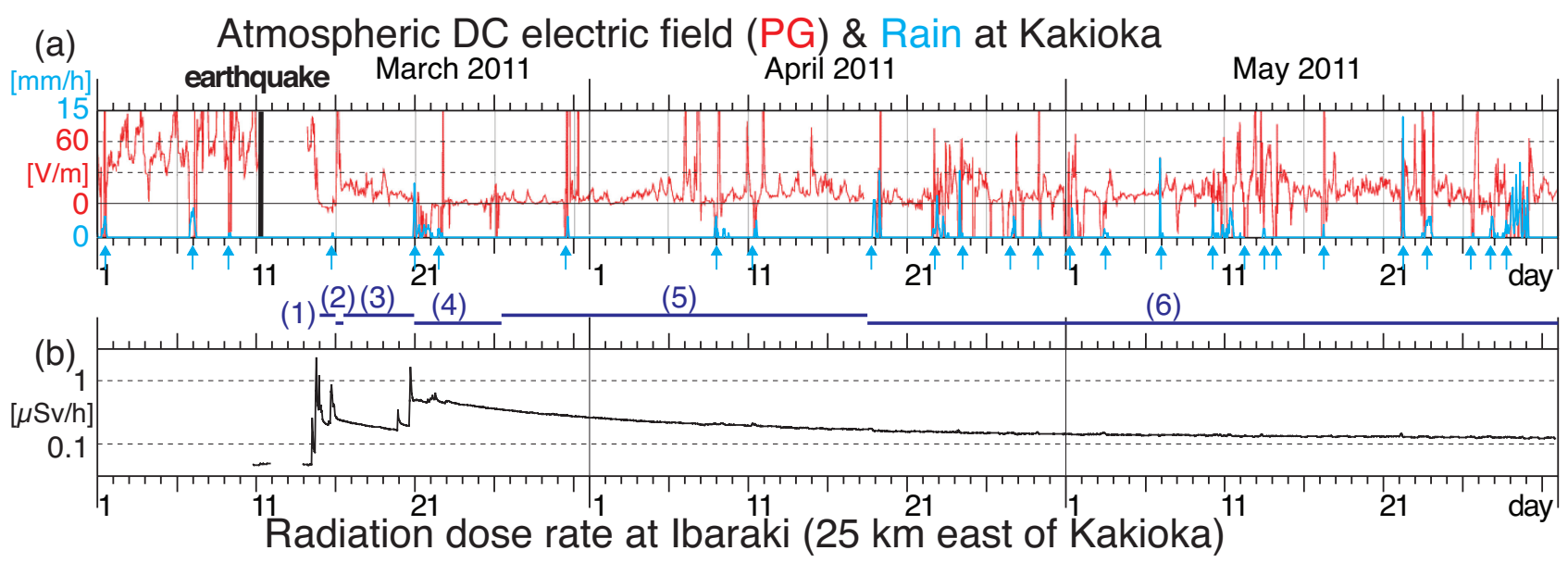

Fig. 1. Three months data before and after the M9.0 earthquake on 11 March 2011: (a) Atmospheric DC electric field vertical component, or potential gradient (PG) at Kakioka station measured by electrostatic sensor (red line) and rainfall at Kakioka (blue line); (b) the radiation dose rate at Ibaraki-cho (nearest station of radiation observation to Kakioka). The time resolutions of the plots are $1 \mathrm{~h}$ (PG data is sampled with $1 \mathrm{~s}$ resolution). The blue vertical arrows below the upper panel indicate the onset of rain events. The numbers (1) to (6) between two panels refer to the six time segments as described in the text and designated by the stepped horizontal lines. The data gap from 06 UT, 11 March to 06 UT, 14 March is due to the power failure caused by the earthquake.

The spike of the radiation dose rate on 20 March is the last one, as one can see in Fig. 1. The termination of the spike-like increase of the radiation level on 20 March is also confirmed by the radiation dose rate data in the other directions from the FNPP (not shown here). The other stations' data also show the wind-driven spread (spike-like peak) on all days during 12-20 March, i.e. the FNPP area was the continuous source of the radioactive dust until 20 March. After the last major spread of the radioactive dust on 20 March, the radiation dose rate continuously decreased with nearly exponential decay. We note that the rain on 20 March was the first major rain in the entire area after the accident, and that this rain most likely caused the majority of suspended radioactive dust in the air near the FNPP to settle on the ground. This explains the termination of the spread of the radioactive dust because no significant change in the status of the release of the radioactive materials from the FNPP facility was reported on 20 March. This means that a substantial amount of radioactive dust stayed in the air before this rain, i.e. after the earlier rains.

Next, we examine the PG behavior that provides additional information on the dynamics of the radioactive materials. We divide the PG data after the initial drop on 14 March into six different periods as marked by stepped lines that are numbered (1)-(6) in Figs. 1 and 3:

1. Near-zero PG over $28 \mathrm{~h}$ around 15 March (Fig. 3a) while the radiation level at Ibaraki-cho at $25 \mathrm{~km}$ east of Kakioka (Fig. 3b) showed two spike-like increases at around 03 UT and 21 UT, both of which are related to the wind direction change. The weather was cloudy with nearly a constant humidity except a short period of minor rain (total $1 \mathrm{~mm}$ ) at around 20 UT, 15 March. No change in the cloud electricity except this rain is indicated by constant standard deviation until 01:20 UT on 16 March (Paper 1). The wind was not measured at Kakioka, but blowing from north or from east during the entire day on 15 March at three stations surrounding Kakioka. The locations of these stations (Kasama, Shimodate, and Tsuchiura) are shown in Fig. 2.

2. Increase of the PG during 01-07 UT, 16 March to more than $50 \mathrm{~V} \mathrm{~m}^{-1}$, and subsequent settlement to about $20 \mathrm{~V} \mathrm{~m}^{-1}$ (Fig. 3a) while the radiation level at Ibarakicho stayed constant (Fig. 3b). Standard deviation of PG (not shown here) has many spikes during this period, indicating the existence of the electrified cloud during the elevated PG. In fact, a weather system passed at the beginning of this episode and mostly cloudy conditions continued. More importantly, this weather system brought first strong wind $\left(>5 \mathrm{~m} \mathrm{~s}^{-1}\right.$ for $1 \mathrm{~h}$ average and $>10 \mathrm{~m} \mathrm{~s}^{-1}$ for instantaneous peaks) together with the first sunshine (sunshine more than $70 \%$ of the time) after the accident on 14 March, during 02-07 UT at Kasama, 01-08 UT at Shimodate, and 02-08 UT at Tsuchiura. The observed strong wind was from west, i.e. from a large angle to the direction of the FNPP.

3. Low but finite (about $20 \mathrm{~V} \mathrm{~m}^{-1}$ ) PG with some fluctuations during 16-20 March (Fig. 3c). The radiation level (Fig. 3d) also stayed constant except for a slight increase together with a spike at around 02 UT, 20 March, although no outstanding signature is recognized in the PG data at this time. This spike corresponds to the first 


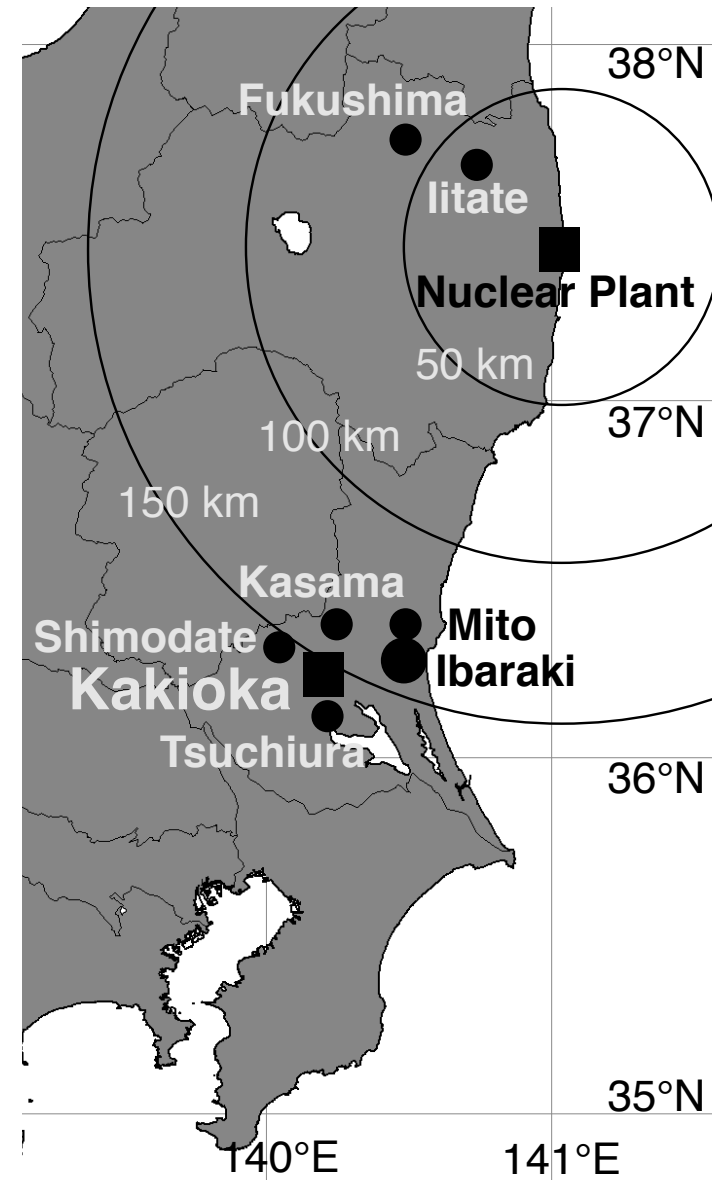

Fig. 2. The locations of the Fukushima Dai-ichi nuclear power plant (FNPP), Kakioka (150 km southwest of FNPP), Ibaraki-cho ( $25 \mathrm{~km}$ east of Kakioka), Mito (30 km northeast of Kakioka), Kasama (17 km north of Kakioka), Shimodate (19 km west of Kakioka), and Tsuchiura (15 km south of Kakioka). For reference, we add Iitate $(40 \mathrm{~km}$ northwest of FNPP) and Fukushima $(60 \mathrm{~km}$ northwest of FNPP), which are reported as highly contaminated region compared to the region in the other direction for the same distance from the FNPP.

continuous wind lasting more than one hour from the FNPP direction at Mito after the end of the last event mentioned above. No rain was observed at Kakioka until 22 UT, 20 March.

4. Intermittent negative PG during the first strong rain from 22 UT, 20 March to 05 UT, 23 March (Fig. 3e). After the rain, the PG settled to near-zero level without daily variation. The radiation dose rate (Fig. 3f) increased spike-like at around 20 UT on 20 March, two hours prior to the rain, and it settled to a new value at the peak of the rain. This value fluctuated until the end of the rain on 23 March.

5. Recovery of daily variation of PG from 26 March to the middle of April. An example period is shown in
$P G$ at Kakioka \& Rain at Kakioka \& at Mito Radiation dose rate at lbaraki \& at Mito
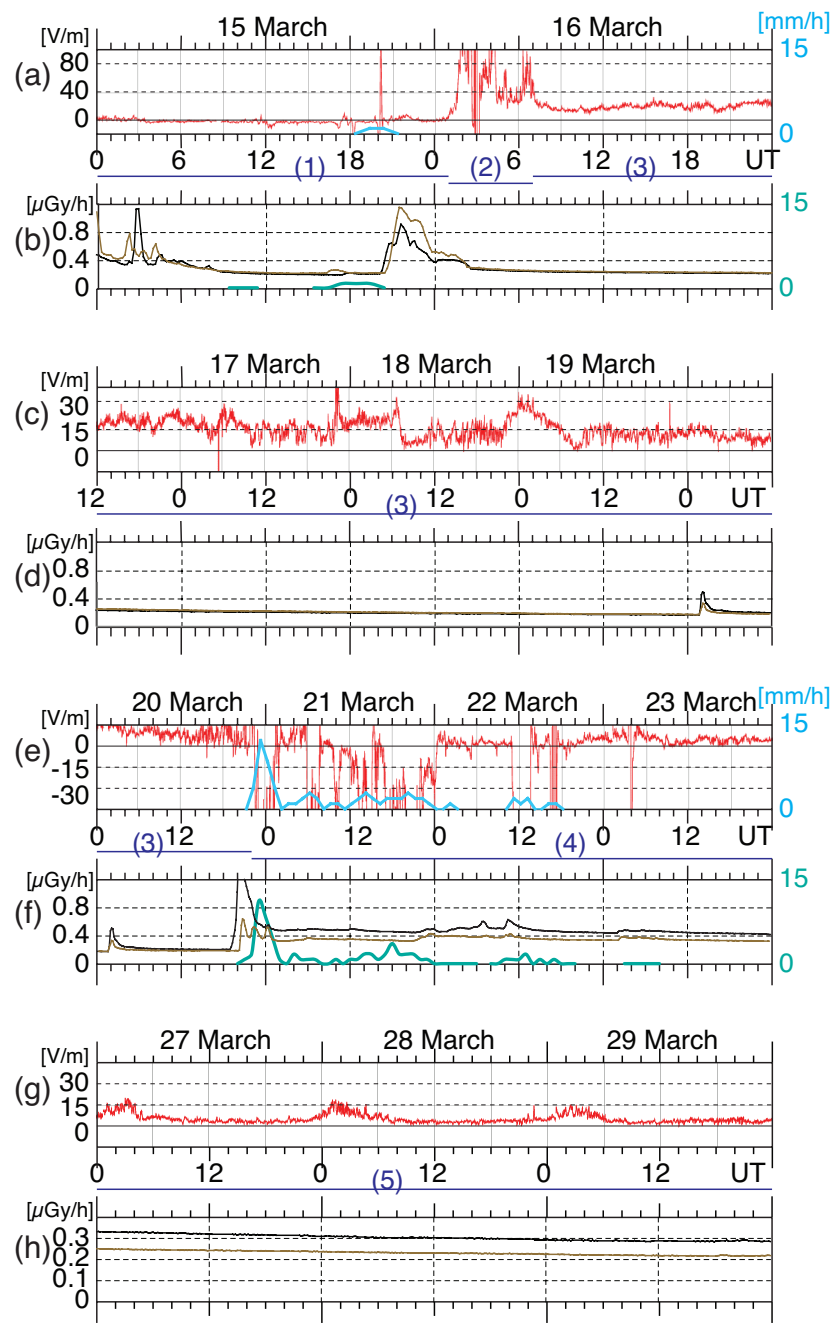

Fig. 3. PG at Kakioka (red line), rainfall at Kakioka (blue line), radiation dose rate at Ibaraki-cho (black line), radiation dose rate at Mito (brown line), and rainfall at Mito (blue-green line) in the same format as Fig. 1 except for the duration and scales: (a) and (b) 15-16 March (48 h); (c) and (d) 16-20 March (96h); (e) and (f) 20-23 March (96h); and (g) and (h) 27-29 March (72 h). Mito is located $15 \mathrm{~km}$ north of Ibaraki-cho (Fig. 2). The ordinate scale for the radiation curves (b), (d), (f), and (h) is linear instead of logarithmic as in Fig. 1, and scaling for (a) and (h) and offset for (e) are different from those for the other respective panels. Numbers (1)-(5) in each panel denotes the same periods as (1)-(5) in Fig. 1, respectively. Note that local noon at Kakioka is near 03 UT.

Fig. $3 g$ and $h$. The nighttime fair-weather baseline PG stayed low while minor recoveries of the baseline PG started, reaching to about $10 \mathrm{~V} \mathrm{~m}^{-1}$ by the end of this period. The radiation dose rate continuously decayed with a half-decay time of about 10 days that corresponds to ${ }^{131} \mathrm{I}$. 
6. Weakening of the daily variation and gradual recovery of nighttime fair-weather baseline after late April, except for few-days episodes of finite PG values (about $20 \mathrm{~V} \mathrm{~m}^{-1}$ ) during 22-25 April and 11-14 May. The decay rate of the radiation dose rate is much slower than that of the previous period, suggesting that the contamination by ${ }^{131}$ I (half-decay time is 8 days) became less significant than those by ${ }^{137} \mathrm{Cs}$ (half-decay time is 30 year) or ${ }^{134} \mathrm{Cs}$ (half-decay time is 2 year).

\section{Interpretation}

Before any interpretation of the data for this single special event, we must consider possible contamination of the measurement system by the radioactive fallout. The entire system is inside a house, a backup system (rotation type) shows very similar data, and leak-tests are made monthly. All indicate that the sensor cannot be contaminated by the radioactive materials. Furthermore, negative spikes during rainy days are as large as a few thousand $\mathrm{V} \mathrm{m}^{-1}$ even on 22,26 , and 30 March, leading us to believe that the insulation system worked as normal.

During the first period marked by (1) in Fig. 1, the nearzero level PG at Kakioka means that the atmospheric electric conductivity increased by at least one order of magnitude due to the radioactive contamination near the ground (Paper 1). No daily variation was recognized. The stable near-zero PG did not change after the first rain (20 UT, 15 March) of $1 \mathrm{~mm}$ or during the spikes of the high radiation level at around 03 UT and 21 UT at both Ibaraki-cho and Mito as shown in Fig. 3a and b. This is somewhat controversial because the value of about $0.2 \mu \mathrm{Gy} \mathrm{h}^{-1}$ at both Ibaraki-cho and Mito is only five times larger than that before the accident (peak value is another five times more), and such an increase does not enhance the electric conductivity by five times or more if the increase of the radiation level is the same at Kakioka. In other words, the radioactive contamination at Kakioka was most likely higher than that at Ibaraki-cho during this period. One obvious candidate is extra stagnation of the wind by trees or interception by trees during the dry contamination (IAEA, 2006, Sect. 3.4). In fact, higher radiation dose rates are reported near the forests than near the rice field at about $40 \mathrm{~km}$ northwest from the FNPP (Kondoh et al., 2011).

The high contamination of the radioactive materials near the ground during this period does not necessarily mean a settlement to the ground as shown in Fig. 4a or 4b. The PG quickly increased to as high as $100 \mathrm{~V} \mathrm{~m}^{-1}$ during the second periods $(16 \mathrm{March})$ and stayed at around $20 \mathrm{~V} \mathrm{~m}^{-1}$ during the third period (16-20 March) as shown in Fig. 3a and c. We cannot have such a quick PG increase (i.e. decrease of the electric conductivity) if the radioactive dust settled to the ground because no electrified cloud was indicated from the standard deviation of PG after 07 UT on 16 March when the PG settled to about $20 \mathrm{~V} \mathrm{~m}^{-1}$. Therefore, the radioactive ma-
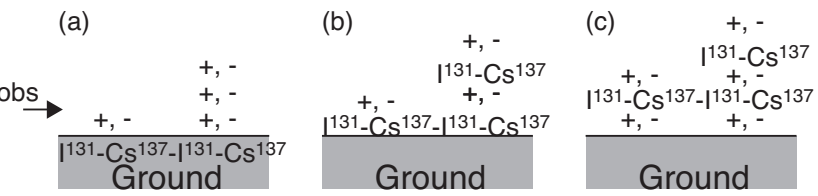

Fig. 4. Illustration of the possible contamination forms of the radioactive materials near the ground: (a) migrating subsurface soil, (b) attaching at the top layer of the soil, (c) suspended in the air near the ground. In each panel, the left-hand side shows the distribution without wind or heat-induced convection and the right hand side shows the distribution when the heat-induced convection or wind lifts particles/ions up from the surface. Subsurface contamination here means that a substantial part of the radiation is absorbed by the soil before it reaches the air. The ionized soil particles at the surface by this absorption might be lifted up by the wind.

terials must have been suspended in the air (e.g. Fig. 4c) or stayed on trees during the first period. In such cases, the large dust particles that normally reduce ion mobility by attachment of ions are expected to be contaminated by radioactive materials, such that the reduction in the atmospheric electric conductivity by the decrease of ion mobility is largely canceled by extra ionization by the radiation from the radioactively contaminated dust. This explains the disappearance of the daily variation of $\mathrm{PG}$.

The enhancement of PG during the second period took place when the weather condition suddenly changed. The strong wind blowing from the non-contaminated direction (large angle to the direction of the FNPP) was observed for the first time after the arrival of the radioactive dust. At the same time, the standard deviation of the PG indicates a sudden increase of the amount of electrified cloud for the first time after the arrival of the radioactive dust. Although the electrified cloud causes large positive PGs for the normal condition, the enhanced electric conductivity (by an order of a magnitude during the first period) predicts much smaller PG than the observed value unless the contamination condition did not change. In other words, the contamination level must have decreased during the second period.

One possible explanation is that the sudden increase of the wind speed lifted the majority of the radioactive dust that was stagnant (suspended in the air or sitting on trees) from near the surface (cf. Fig. 4c) and transported it away from Kakioka. This scenario agrees with the observed increase of PG during both the second period (affected by the electrified cloud) and the third period (not affected by electrified cloud on $16 \mathrm{March}$ ). It is possible that strong wind lifts a majority of the radioactive material if it is not settled to the ground.

The settlement of the radioactive dust to the ground was observed between the third period and the fourth period (Fig. 3e and f), i.e. during the second rain at Kakioka (22 UT, 20 March to 02 UT, 22 March) right after the arrival of the last radioactive dust plume. The PG settled to near-zero after this rain while the radiation dose rate at Ibaraki-cho and 
Mito increased to about $0.4 \mu \mathrm{Gy} \mathrm{h}^{-1}$, i.e. nearly 10 times the value before the accident, enough to increase the electric conductivity as much as 10 times if the nucleus density is high (Rosen and Hofmann, 1981; Makino and Ogawa, 1985). This type of change has been observed soon after the Chernobyl disaster (Tuomi, 1988, 1989) or after nuclear tests (Harris, 1955), and is known as the result of rain-induced radioactive fallout (wet contamination), which causes settlement of the fallout material to the ground.

This reinforces our interpretations that the radioactive materials during the first period with near-zero PG did not settle to the soil but were suspended near the ground as illustrated in Fig. 4c, and that a large part of these suspended radioactive materials in the air was lifted up from the surface (including trees) and transported away by the first strong wind after the accident, i.e. during the second period. The remaining radioactive materials near the ground after this wind were not enough to keep atmospheric electric conductivity as high as during the first period.

During the second rain at Kakioka at the beginning of the fourth period (Fig. 3e and f), large negative PG bays of about $-300 \mathrm{~V} \mathrm{~m}^{-1}$ are observed. Large negative values are normally associated with rain together with the rain clouds, and the observed values are not affected very much by the atmospheric conductivity (which must have been increased at least by an order of magnitude). This is not surprising because the determining factors of the PG values are different between for positive PG cases (downward electric field) and negative PG cases (upward electric field). For the positive PG case, the ratio of the space charge (ionosphere) and atmospheric conductivity normally determines the PG value, whereas for the negative PG case, the ratio of the space charge (cloud) and the negative current carried by the raindrop determines the PG value. In the latter case, atmospheric conductivity plays only a negligible role.

After the second rain caused the radioactive dust to settle on the ground, the PG stayed at near zero during the fourth period until 25 March as shown in Fig. 1. Afterward, the PG started to show a regular daily variation with a peak at around 01-03 UT (10-12 local time) in the fifth period as shown in Fig. 3g. This pattern is similar to typical summer daily variation at Kakioka (single enhancement during 20-04 UT (0513 local time) at peak around 01 UT according to 50 years of observation) except the near-zero baseline and amplitude. The mechanism of the daily variation during the fifth period is similar to the PG increase during the second period, i.e. lifting of the radioactive dust away from near the surface to higher altitudes, but by the daily convective wind. Gradual drying out of the surface (both soil and trees) allows more radioactive materials to be lifted from the surface by the daily convection as illustrated in Fig. 4b. The daily variation also exists in the radiation dose rate, but the pattern is different at different places. Therefore, one cannot simply compare it to the PG variation at Kakioka (in fact, daily variation of the radiation dose rate is not visible in Fig. 3 h).
The nighttime near-zero baseline of the PG at Kakioka also slowly recovered during sunny days, but recovery is somewhat interrupted to set back to near zero on 8 and 18 April. One may wonder if these resets are real resets of the PG or simply due to weather. Since 8-11 April and 18-24 April were continuously cloudy or rainy, and since the radiation dose rate constantly decayed without any setback during the entire period, these resets of the baseline to the near-zero level could simply be associated with the cloudy or rainy weather. However, the baseline PG values during clear sky also indicate the reset of the baseline PG: the baseline PG values on 12-14 April (clear sky) are similar to those on 45 April (clear sky), while that of 25-28 April (clear sky on 25 April and partially cloudy on 26 and 28 April) is less than these values. Considering that the decay time of free charges in the air-earth system is less than $1 \mathrm{~h}$, the reset of the baseline PG on 8 and 18 April can be real ones due to secondary transport of the radioactive materials.

According to the Chernobyl experience, trees intercept the radioactive fallout quite effectively, causing delayed contamination of the ground (IAEA, 2006, Sect. 3.4). If this process happened at Kakioka during April, one can explain the resets of the baseline PG on 8 and 18 April. Such a new contamination of the ground is not necessarily only from the trees but could originate from the upwind direction or from high altitude. In these scenarios, the minor recovery of the baseline PG can be due to gradual migration to the subsurface or removal by wind during dry periods (cf. the same mechanism as the recovery of the daily variation) or both.

To examine whether there is any substantial transport of the radioactive materials, we compare the radiation dose rate between different stations that are located closely to each other, as shown in Fig. 5. Figure 5 shows 80-day profiles of ratios of radiation dose rate from three stations near Ibarakicho compared to the value at Ibaraki-cho. The relative value continuously changed toward unity until around 20 April, indicating a systematic secondary transport of radioactive materials either from high contamination areas to low contamination areas within $15 \mathrm{~km}$ or from thick altitude distribution to thin distribution near the ground. After 20 April, the ratio in Fig. 5 stayed rather constant, and this transition date is the same as the transition from the fifth period to the sixth period that is judged from the PG behavior in Fig. 1.

The same type of analyses at 12 stations within $100 \mathrm{~km}$ from the FNPP (Yamauchi, 2012) also indicate inter-regional secondary transport of radioactive materials from high contamination areas to low contamination areas until the end of April. Figure 5 also shows a clear change at Hiroura and Onuki on 8 April, on the rainy day. Thus, the offsetting of the Kakioka's PG can be related to the change in the radiation dose rate, which was not obvious for Ibaraki-cho or Mito.

We next consider the sixth period that is characterized by the disappearance of the daily variation. The PG recovery was no longer interrupted by the rain if we compare sunny days. Both characteristics indicate a settlement of the 


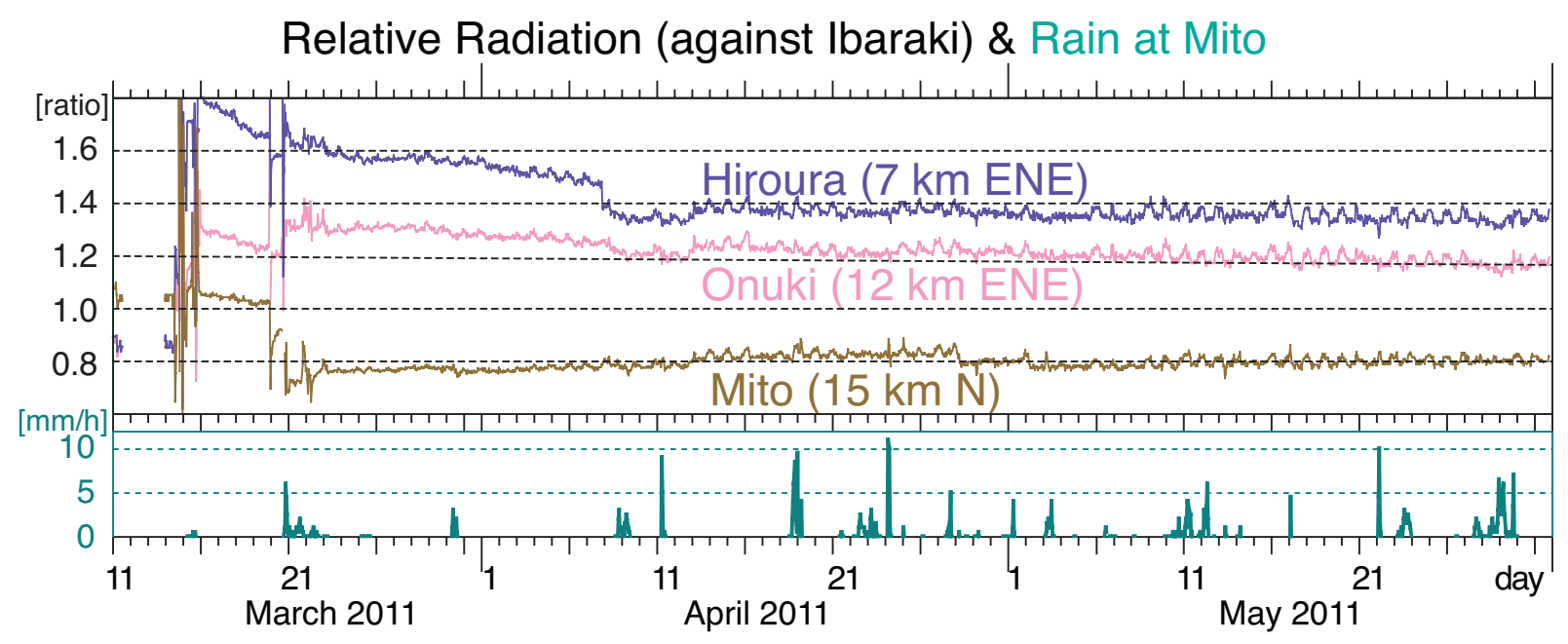

Fig. 5. Top panel: Relative values of the radiation dose rate at three stations near Ibaraki-cho over the value at Ibaraki-cho during MarchMay 2001. The east-northeast (ENE) direction is toward the sea (cf. Fig. 2), whereas north (N) direction is toward the nuclear plant (FNPP). Bottom panel: rainfall at Mito. Both data are hourly values.

radioactive materials to the ground such that the settled radioactive materials are no longer lifted up from the surface by the daily wind even during dry periods, as illustrated in Fig. 4a. The settlement to the ground includes partial migration of radioactive materials to the subsurface (Fig. 4a) because repeated rains help fix the radioactive materials to the soil at both surface and subsurface (IAEA, 2006, Sects. 3.1, 3.3 , and 3.5). Once the radioactive materials migrate to subsurface, radiation from there is absorbed by the soil particles, making the radiation dose rate small while ionizing the soil particles (IAEA, 2006, Sects. 4.2, 4.3). The majority of the ionized soil particles most likely stayed on the ground, so that the daily variations during the sixth period are expected to be less than those during the fifth period.

\section{Summary and conclusion}

The PG data from Kakioka, together with the radiation dose rate from the nearest station (located about $25 \mathrm{~km}$ away), show the detailed processes of the transport, migration, and dynamics of the ionizing radioactive materials. We have shown six different periods that represent different forms of the contamination.

(1) The initial drop of the PG to almost zero during 1415 March is most likely due to radioactive dust suspended in the air near the ground during cloudy weather. (2) An episode of PG increase to more than $50 \mathrm{~V} \mathrm{~m}^{-1}$ on $16 \mathrm{March}$ is most likely due to the re-suspension of the radioactive dust from the surface (ground and trees) to the air and subsequent removal from Kakioka by a first strong wind $\left(>5 \mathrm{~m} \mathrm{~s}^{-1}\right.$ in hourly average) from the non-contaminated area. (3) Low but finite values of the PG during 16-20 March most likely reflect a reduced amount of radioactive material near the ground after the above wind transported away the majority of the suspended radioactive dust. (4) Very low values of the PG after the substantial rain on 20-22 March most likely reflect settlement of the radioactive material by the rain-induced fallout. (5) Temporal recovery of daily variations from the end of March to the middle of April with low nighttime fair-weather baseline PG most likely reflects re-suspension of the radioactive dust into the air from the ground and trees, and subsequent transport to the other region or fallout to the ground until late April. (6) Weakening of the daily variation and gradual recovery of the nighttime fair-weather baseline after the mid-April suggests a complete settlement of the radioactive material to the ground with partial migration to the subsurface.

Thus, the PG observation gives extra information on the dynamics and re-distribution of the radioactive materials, which cannot be monitored only by the radiation dose rate. The information on the suspension of the radioactive dust obtained here is particularly important in understanding the internal dose that the local residents have received as the result of the Fukushima nuclear accident. In this report, we did not examine all changes in the weather/wind on the hourly scale, human effects that produce other types of dust, spread of the radioactive materials into the water, nor the possible effect of the ionizing radioactive dust in changing the weather through the electrical effects on cloud microphysics.

Acknowledgements. The atmospheric electricity (PG) data is available to the public through http://www.kakioka-jma.go.jp/cgi-bin/ plot/plotSetNN.pl?lang=en. We thank T. Toya for his advice on the PG data. The radiation dose rates are published on the web sites of Ibaraki-cho prefecture (http://www.pref.ibaraki.jp/20110311eq/ index2.html). The meteorological data was provided by Japan Meteorological Agency through http://www.jma.go.jp/jma/indexe. html. The relation between the radiation dose rate and the wind 
direction near Ibaraki-cho that was discussed in relation to Fig. 5 can be seen in 10-min resolution movie of 40 stations at http://dl. dropbox.com/u/8076743/eq2011/Radio20110315-31b.mov). The lead author (MY) wishes to thank Sweden programs of providing help for physically disabled individuals which have made it possible for him to conduct this work.

Topical Editor P. Drobinski thanks B. Tinsley and A. Bennett for their help in evaluating this paper.

\section{References}

Hamilton, R. A. and Paren, J. G.: The influence of radioactive fallout on the atmospheric potential gradient, Meteorol. Mag., 96, 81-85, 1967.

Harris, D. L.: Effects of radioactive debris from nuclear explosions on the electrical conductivity of the lower atmosphere, J. Geophys. Res., 60, 45-52, 1955.

Harrison, R. G.: Twentieth century atmospheric electrical measurements at the observatories of Kew, Eskdalemuir and Lerwick, Weather, 58, 11-19, 2003.

IAEA: Environmental Consequences of the Chernobyl Accident and Their Remediation: Twenty Years of Experience, 181pp, International Atomic Energy Agency, Vienna, http://www-pub. iaea.org/mtcd/publications/pdf/pub1239_web.pdf, 2006.

Israelsson, S. and Knudsen, E.: Effect of radioactive fallout from a nuclear power plant accident on electrical parameters, J. Geophys. Res., 91, 11909-11910, 1986.

Kondoh, A., Yamaguchi, H., Hayakawa, Y., and Shimojo, R.: Characteristics of dose rate distribution around litate-mura caused by the accidents of Fukushima Daiichi Nuclear Power stations, J. Rural Planning, 30, 121-122, 2011 (in Japanese).

Makino, M. and Ogawa, T.: Quantitative Estimation of Global Circuit, J. Geophys. Res., 90, 5961-5966, 1985.

MEXT: Distribution map of radiation dose around Fukushima Daiichi \& Dai-Ni NPP, press release by Ministry of Education, Culture, Sports, Science and Technology (MEXT), Japan, http: //www.mext.go.jp/english/incident/1305901.htm, 2011.
NISA: The Accident at TEPCO's Fukushima nuclear power stations, Report of Japanese government to the IAEA ministerial conference on nuclear safety, 7 June 2011, chapter VI, press release by Nuclear and Industrial Safety Agency (NISA), Japan, http://www.iaea.org/newscenter/focus/ fukushima/japan-report/, 2011.

Pierce, E. T.: Some calculations on radioactive fallout with especial reference to the secular variations in potential gradient at Eskdalemuir, Scotland, Pure Appl. Geophys., 42, 145-151, 1959.

Rosen, J. M. and Hofmann, D. J.: Balloon-borne measurements of electrical conductivity, mobility, and the recombination coefficient, J. Geophys. Res., 86, 7406-7410, 1981.

Rycroft, M. J., Israelsson, S., and Price, C.: The global atmospheric electric circuit, solar activity and climate change, J. Atmos. Sol. Terr. Phys, 62, 1563-1576, 2000.

Rycroft, M. J., Harrison, R. G., Nicoll, K. A., and Mareev, E. A.: An overview of Earth's global electric circuit and atmospheric conductivity, Space Sci. Rev., 137, 83-105, doi:10.1007/s11214 008-9368-6, 2008.

Shigeno, N., Takizawa, T., Itoh, N., Yokoyama, M., and Owada, T.: Preliminary test for atmospheric electricity measured using an electrostatic sensor, Gijutsu Hookoku, 112, 8-13, 2001.

Takeda, M., Yamauchi, M., Makino, M., and Owada, T.: Initial effect of the Fukushima accident on atmospheric electricity, Geophys. Res. Lett., 38, L15811, doi:10.1029/2011GL048511, 2011.

Tuomi, T. J.: Observations of atmospheric electricity 1986, Geophysical Publications, 7, 551.506.1, Finish Meteorological Institute, Helsinki, 61 pp., 1988.

Tuomi, T. J.: Ten Year Summary 1977-1986 of Atmospheric Electricity Measured at Helsinki-Vantaa Airport, Finland, Geophysica, 25, 1-20, 1989.

Williams, E. R.: The global electrical circuit: A review, Atmos. Res., 91, 140-152, doi:10.1016/j.atmosres.2008.05.018, 2009.

Yamauchi, M.: Secondary wind transport of radioactive materials after the Fukushima accident, Earth, Planet, Space, submitted, 2012. 